\title{
Echogenic Mass Lesion within the Main Pulmonary Artery in a Neonate
}

Lae-Eun Jeong, $\mathrm{MD}^{1}$, Jae Yoon $\mathrm{Na}, \mathrm{MD}^{1}$, June Huh, $\mathrm{MD}, \mathrm{PhD}^{1}$, I-Seok Kang, $\mathrm{MD}, \mathrm{PhD}^{1}$, Ji-Hyuk Yang, $\mathrm{MD}, \mathrm{PhD}^{2}$, Tae-Gook Jun, $\mathrm{MD}, \mathrm{PhD}^{2}$, and Jin Young Song, $\mathrm{MD}, \mathrm{PhD}^{1}$

Departments of ${ }^{1}$ Pediatrics and ${ }^{2}$ Thoracic and Cardiovascular Surgery, Samsung Medical Center, Sungkyunkwan University School of Medicine, Seoul, Korea

\section{ABSTRACT}

Here we present a rare case of pulmonary arterial thrombosis associated with a ductus arteriosus aneurysm that caused severe pulmonary stenosis. A 5-day-old newborn was admitted to our hospital for the evaluation of an intracardiac mass-like lesion found after the detection of a cardiac murmur. Echocardiography and heart computed tomography revealed a mass-like lesion measuring $8.1 \mathrm{~mm}$ in diameter across the distal main pulmonary artery to the proximal left pulmonary artery resulting in localized severe stenosis of the left pulmonary artery. Left pulmonary artery angioplasty for surgical resection of the thrombus revealed that the mass was adherent to the proximal part of the left pulmonary artery anterior wall and extended to the ductus arteriosus. Histological examination of the mass showed an old thrombus with dystrophic calcification. Five months after surgery, follow-up echocardiography showed that the left pulmonary artery peak pressure gradient had decreased but the proximal left pulmonary artery stenosis remained. Cardiac catheterization and balloon angioplasty successfully relieved the pulmonary stenosis.

Key Words: Infant, newborn; Pulmonary artery; Ductus arteriosus

\section{INTRODUCTION}

Thrombi and vegetations are the most common types of cardiac masses found on echocardiography. Cardiac tumors are exceedingly rare and mostly secondary. Neonatal arterial thrombosis, a rare clinical condition, predominantly occurs in the aorta, and the majority of arterial thrombi are iatrogenic and associated with an indwelling central line. Pulmonary artery thrombosis is even less commonly reported, and those reports were from a fetal ductus arteriosus ${ }^{1}$. Thrombosis in the pulmonary artery can be present with pulmonary stenosis and persistent pulmonary hypertension of the newborn ${ }^{2}$.

Here we report a case of main pulmonary artery (MPA) thrombosis in a neonate that was suspected to have originated from a ductus arteriosus aneurysm.
Received: 13 March 2020

Revised: 27 April 2020

Accepted: 29 April 2020

Correspondence to: Jin Young Song, $\mathrm{MD}, \mathrm{PhD}$

Department of Pediatrics, Samsung Medical Center, Sungkyunkwan University School of Medicine, 81 Irwonro, Gangnam-gu, Seoul 06351, Korea

Tel: +82-2-3410-3537

Fax: +82-2-3410-0830

E-mail: amyjs.song@samsung.com

Copyright(c)

By Korean Society of Neonatology.

All right reserved.

This is an Open-Access article distributed under the terms of the Creative Commons Attribution Non-Commercial License (http:// creativecommons.org/licenses/by-nc/4.0), which permits unrestricted non-commercial use, distribution, and reproduction in any medium, provided the original work is properly cited. 


\section{CASE REPORT}

A 5-day-old newborn was admitted to our hospital for evaluation of an intracardiac mass-like lesion found after the detection of a cardiac murmur. The patient was a male neonate delivered at $39^{+1}$ weeks' gestation by emergency Cesarean section due to premature rupture of the membranes. He did not require resuscitation. Maternal medical history was unremarkable, and there was no family history of congenital heart disease, oncologic disease, or thrombophilia.

After delivery, he transitioned well and was admitted to the mother-baby unit. He demonstrated good oral intake and good activity. Five days after birth, a cardiac murmur was found on physical examination despite the patient remaining asymptomatic. Echocardiography at a nearby hospital revealed a mass lesion within the distal MPA, and the patient was transferred to our hospital for further evaluation.

On admission, a cardiovascular examination revealed a grade $2 / 6$ systolic murmur at the left upper sternal border. The rest of the physical examination was unremarkable. Chest radiography showed a normal cardiac shadow and normal pulmonary vascularity. Echocardiography performed using a GE Vivid E95 ultrasound machine (GE Healthcare, Chicago, IL, USA) detected an outer echogenic inner echolucent oval-shaped mass within the distal MPA. The mass caused increased left pulmonary artery (LPA) flow velocity up to $3.29 \mathrm{~m} / \mathrm{sec}$, and the pressure gradient

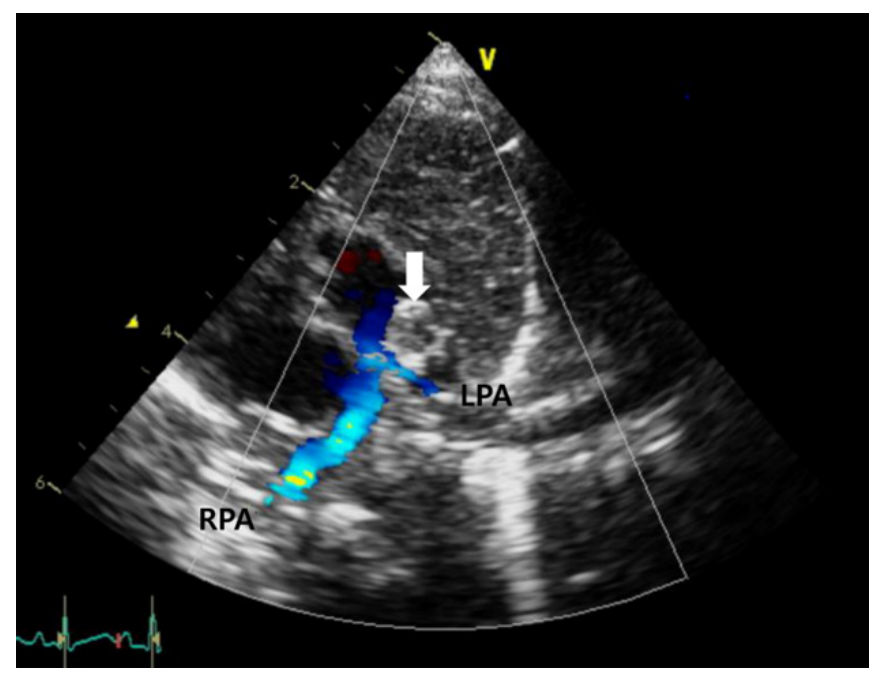

Figure 1. The parasternal short-axis view on transthoracic echocardiography revealed an oval-shaped mass (arrow) protruding from the lumen of the distal main pulmonary artery (MPA) to the proximal left pulmonary artery (LPA) causing LPA stenosis. Abbreviation: RPA, right pulmonary artery. increased to $43.3 \mathrm{~mm} \mathrm{Hg}$. Neither ductus arteriosus nor a septal defect was observed on echocardiography (Figures 1,2).

Heart computed tomography (CT) conducted using a Siemens SOMATOM Definition f64 (Siemens Healthineers, Erlangen, Germany) revealed that the mass lesion extended across the distal MPA to the proximal LPA. The mass measured approximately 8.1 $\mathrm{mm}$ in diameter and caused localized severe stenosis of the LPA (Figure 3).

Blood tests were performed to rule out infection and hypercoagulation conditions. White blood cell count and inflammatory markers such as C-reactive protein were normal. Platelet count, prothrombin time (international normalized ratio), activated partial thromboplastin time, fibrinogen, antithrombin III, and thromboelastometry findings were also normal.

In the surgical field, the mass was observed on the LPA side of the MPA bifurcation tightly adherent to the MPA anterior wall. It was completely resected from the MPA wall and LPA angioplasty was performed. The opposite end of the mass protruded inside the ductus arteriosus. Ductus ligation and resection were performed on the side of the aorta (Figure 4).

The patient was stable after surgery and his postoperative course was smooth. The final pathology report identified the mass as an old thrombus with dystrophic calcification (Figure 5). On the fifth postoperative day, the patient was discharged without perioperative complications.

Five months after surgery, follow-up echocardiography performed in the outpatient department showed that the LPA peak pressure gradient had decreased but the proximal LPA stenosis remained. Therefore, cardiac catheterization and balloon angio-

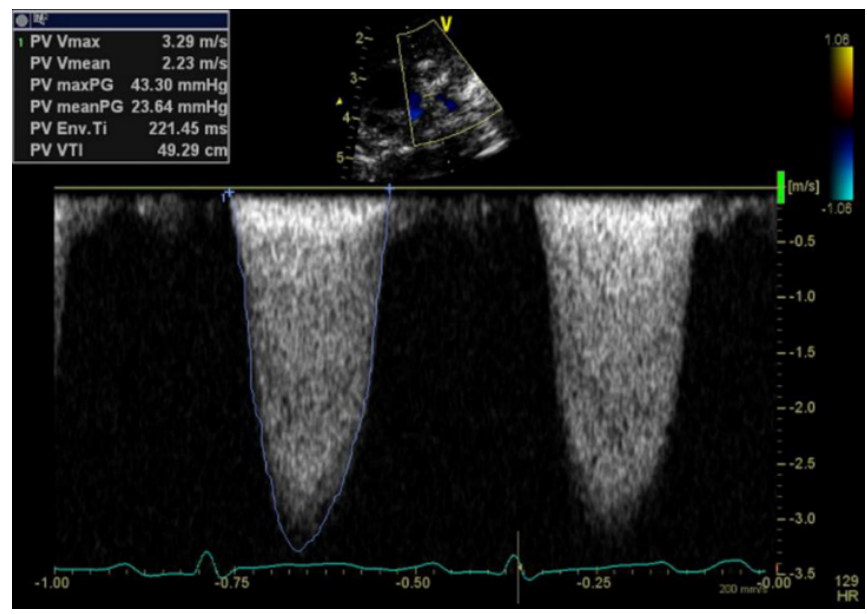

Figure 2. Left pulmonary artery flow velocity estimated by Doppler echocardiography revealed an increased left pulmonary artery pressure. 


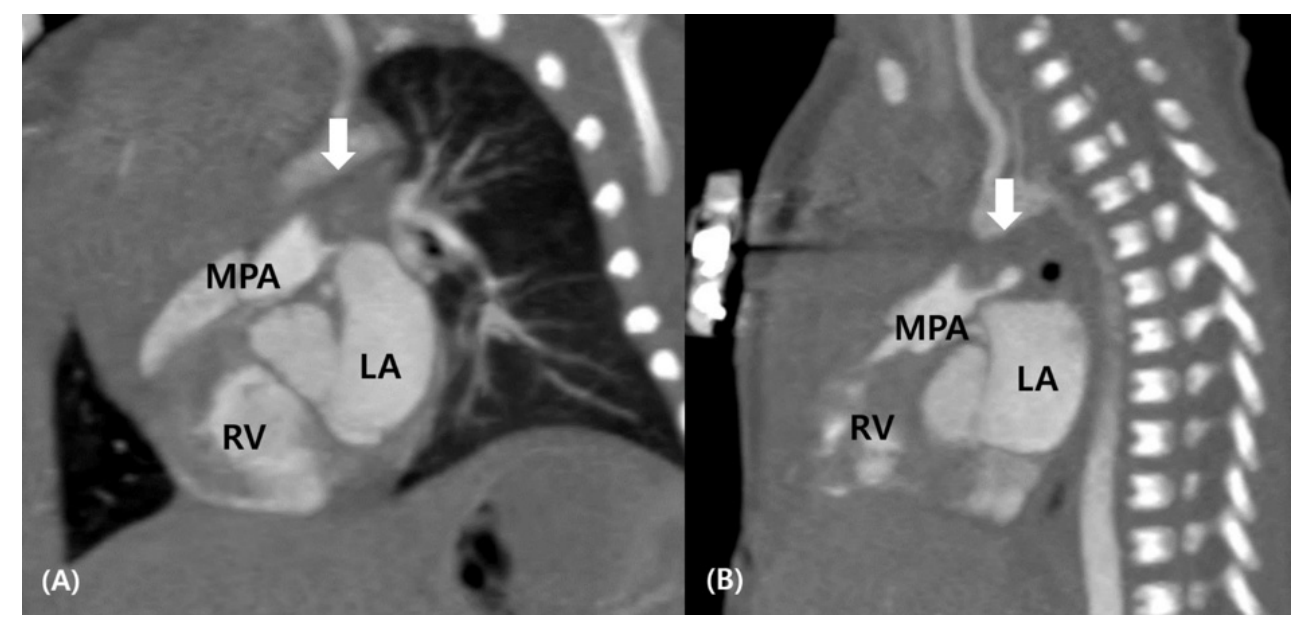

Figure 3. Sagittal (A) and left pulmonary artery (B) views of cardiac computed tomography showing the mass (arrows) in the lumen of the main pulmonary artery. Abbreviations: LA, left atrium; MPA, main pulmonary artery; RV, right ventricle.

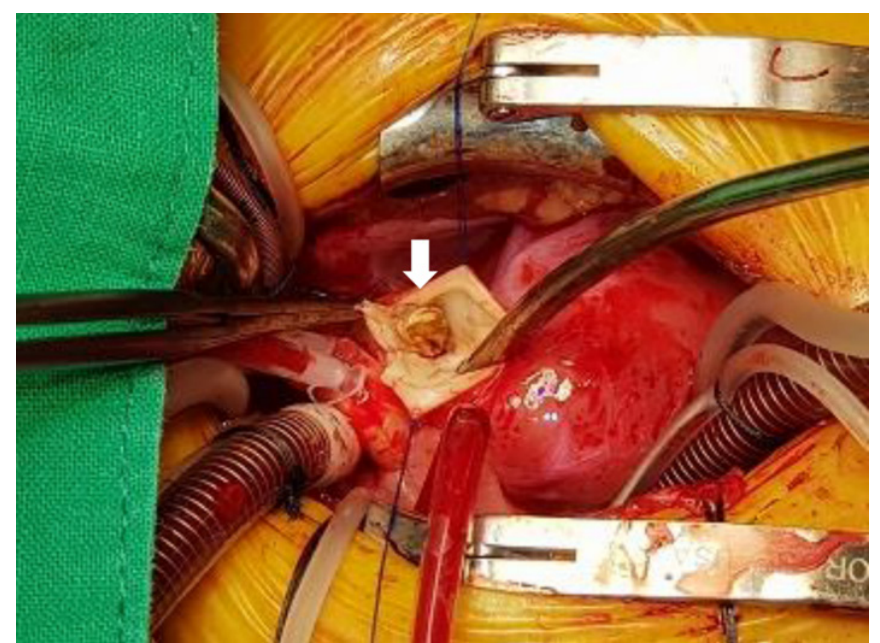

Figure 4. Intraoperative image showing that the mass (arrow) was tightly attached to the left pulmonary artery anterior wall just below the main pulmonary artery bifurcation. It seemed to extend from the main pulmonary artery bifurcation to the patent ductus arteriosus.

plasty were performed to alleviate the residual LPA stenosis. The pre-catheterization proximal LPA was $2.6 \times 2.6 \mathrm{~mm}$; after balloon angioplasty, it expanded to $4.5 \times 5.8 \mathrm{~mm}$. The LPA peak pressure gradient decreased to the normal range after the procedure.

\section{DISCUSSION}

Previous studies described the major predisposing factors for neonatal pulmonary arterial thrombus as central venous lines, infection, congenital heart disease, and inherited thrombophilia ${ }^{3)}$.

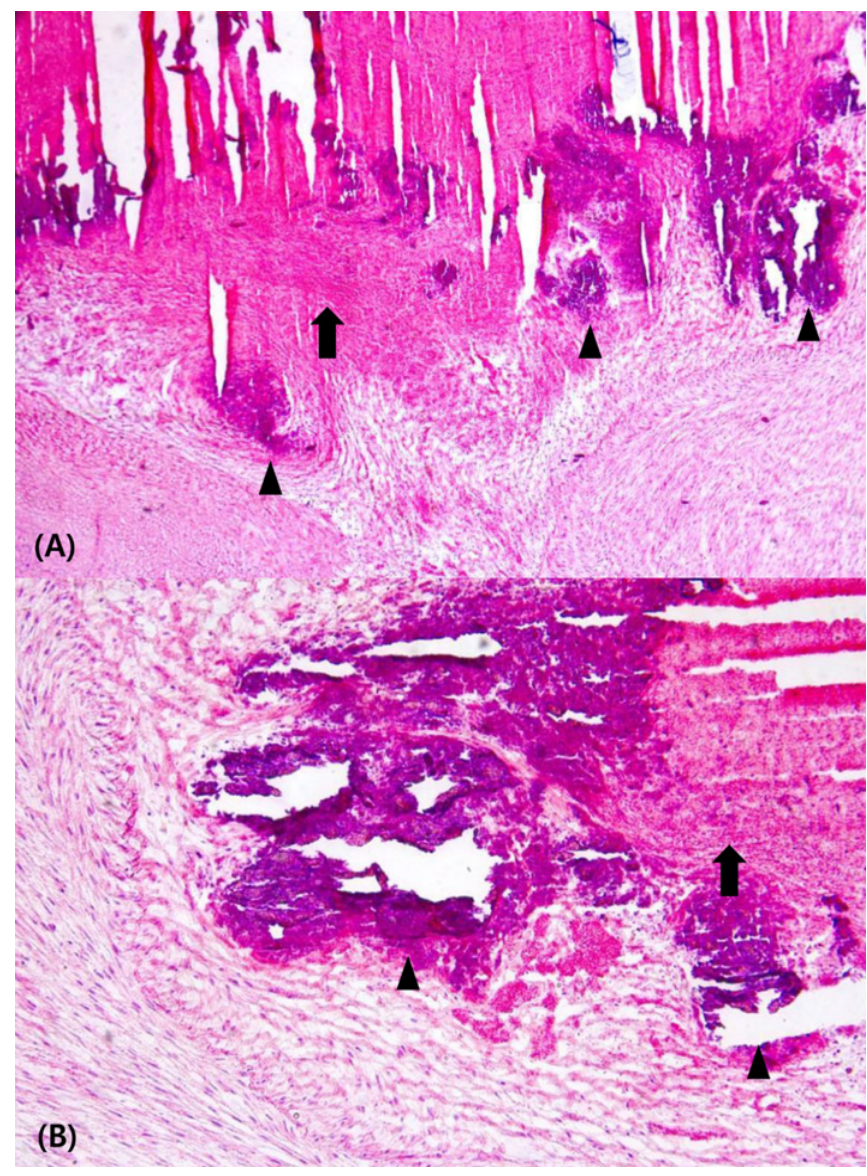

Figure 5. Histologic examination of the tissue removed from the left pulmonary artery showing an old thrombus (arrows) with dystrophic calcifications (arrowheads). (A) H\&E, $\times 100$; (B) H\&E, $\times 200$. 
Our patient had no central lines, and laboratory tests and echocardiography showed no signs of infection or congenital heart disease. The patient's thrombus resided at the junction of the MPA and LPA and protruded to the patent ductus arteriosus. McArdle et al. ${ }^{4}$ reported a case of a neonate with a large mass within the MPA and LPA. In that case, the lesion caused a mass effect with resultant pulmonary stenosis and was eventually diagnosed as a large thrombus presumed to have originated from a ductus arteriosus aneurysm. Considering the chest CT findings and the location and shape of the thrombus confirmed in the surgical field, our patient also appeared to have a ductus arteriosus aneurysm and a thrombus within it, although this was not clearly identified histologically.

Ductus arteriosus aneurysm is a congenital cardiac abnormality occurring in $0.8 \%$ to $8.8 \%$ of all newborns ${ }^{5,6}$. The pathogenesis of the aneurysmal wall is unclear but thought to be related to abnormal intimal cushion formation, decreased elastin fibers during natural involution of the ductus arteriosus, and delayed closure at the aortic segment of the ductus arteriosus with exposure of the ductal wall to high pressures ${ }^{7}$. Dyamenahalli et al. ${ }^{8)}$ reported a multicenter retrospective study of the clinical characteristics of ductus arteriosus aneurysm. In this study, six of the 24 patients with ductus arteriosus aneurysm had underlying disorders such as trisomy 21, trisomy 13, Smith-Lemli-Opitz syndrome, type IV Ehlers-Danlos syndrome, or Marfan's syndrome. These findings suggest that an intrinsic vulnerability of the ductus arteriosus could be associated with aneurysm formation in the neonate or infant. Most of the previously reported ductus arteriosus aneurysms regressed spontaneously within a few weeks. However, ductus arteriosus aneurysm is rarely associated with complications, such as spontaneous rupture, thromboembolism, or compression of the adjacent thoracic structures ${ }^{9}$. Among patients with ductus arteriosus aneurysms, the reported incidence of thrombosis is approximately $30 \%^{6,8)}$. The mechanism of thrombus formation is presumed to be stagnant blood pooling inside the aneurysm structure, leading to thrombosis ${ }^{10,11)}$.

In conclusion, the present case is a rare example of pulmonary arterial thrombosis causing severe pulmonary stenosis most likely due to ductus arteriosus aneurysm and thrombus formation in the course of ductus arteriosus obliteration. After open surgical resection of the thrombus with LPA angioplasty, the residual pulmonary stenosis was relieved by balloon angioplasty.

\section{ARTICLE INFORMATION}

\section{Ethical statement}

This study was approved by the Institutional Review Board of Samsung Medical Center (approval number: SMC 2019-11-102006). Written informed consent by the patients was waived due to a retrospective nature of our study.

\section{Conflicts of interest}

No potential conflict of interest relevant to this article was reported.

\section{Author contributions}

Conception or design: L.E.J., J.Y.N., I.S.K., J.Y.S.

Acquisition, analysis, or interpretation of data: L.E.J., J.Y.N., J.H.Y., T.G.J., J.Y.S.

Drafting the work or revising: L.E.J., J.H., I.S.K., J.Y.S.

Final approval of the manuscript: J.Y.S.

\section{ORCID}

Lae-Eun Jeong https://orcid.org/0000-0001-8975-8958

Jin Young Song https://orcid.org/0000-0002-9660-5949

\section{Acknowledgments}

None

\section{REFERENCES}

1. van Schendel MP, Visser DH, Rammeloo LA, Hazekamp MG, Hruda J. Left pulmonary artery thrombosis in a neonate with left lung hypoplasia. Case Rep Pediatr 2012;2012:314256.

2. Sawyer T, Antle A, Studer M, Thompson M, Perry S, Mahnke CB. Neonatal pulmonary artery thrombosis presenting as persistent pulmonary hypertension of the newborn. Pediatr Cardiol 2009; 30:520-2.

3. Dijk FN, Curtin J, Lord D, Fitzgerald DA. Pulmonary embolism in children. Paediatr Respir Rev 2012;13:112-22.

4. McArdle DJ, Paterson FL, Morris LL. Ductus arteriosus aneurysm thrombosis with mass effect causing pulmonary hypertension in the first week of life. J Pediatr 2017;180:289.

5. Hornberger LK. Congenital ductus arteriosus aneurysm. J Am Coll Cardiol 2002;39:348-50.

6. Jan SL, Hwang B, Fu YC, Chai JW, Chi CS. Isolated neonatal ductus arteriosus aneurysm. J Am Coll Cardiol 2002;39:342-7.

7. Lund JT, Jensen MB, Hjelms E. Aneurysm of the ductus arterio 
sus. A review of the literature and the surgical implications. Eur J Cardiothorac Surg 1991;5:566-70.

8. Dyamenahalli U, Smallhorn JF, Geva T, Fouron JC, Cairns P, Jutras L, et al. Isolated ductus arteriosus aneurysm in the fetus and infant: a multi-institutional experience. J Am Coll Cardiol 2000;36:262-9.

9. Deeg KH, Ruffer A. Thrombus formation and arterial dissection of the wall of the left pulmonary artery caused by an aneurysm of the ductus arteriosus. Ultraschall Med 2019;40:85-6.

10. Doreswamy SM, Twiss J, Predescu D, Shivananda SKP. Extending thrombus within the PDA in an infant with tetralogy of Fallot and pulmonary atresia: an averted disaster. J Clin Neonatol 2015;4:42-5.

11. Sattar P, Ehrensperger J, Ducommun JC. Thrombosed aneurysmal nonpatent ductus arteriosus: a case report. Pediatr Radiol 1996;26:207-9. 